\title{
Observations on some Diurnal Rhythms in Depressive Illness
}

\author{
A. ELITHORN,* M.A., M.D., D.P.M.; P. K. BR.IDGES,* M.D., D.P.M. ; MARY C. LOBBAN, $\dagger$ M.A., PH.D., M.R.C.v.s. \\ BARBARA E. TREDRE, $†$ PH.D.
}

Brit. med. F., 1966, 2, 1620-1623

There are now a large number of potent physical treatments available for the depressed patient. Some of these carry an appreciable morbidity, and it is no longer appropriate that the physician should choose between them either at random or according to personal preference.

The concept of the endogenous depressive process as a physiological state, aetiologically distinct from depressive changes which are dependent on psychological mechanisms, is widely accepted on the Continent, but is viewed with suspicion by many workers in America and in this country. Though it is often alleged that psychiatric diagnosis is a barren exercise, patients and the relatives of patients who suffer from manic-depressive disease can sometimes distinguish with clarity between depressive attacks which are physiological in type and depressive spells which are reactive in origin and symptomatically different. These physiological depressions may arise, proceed, and remit without regard to psychological events.

The concept of manic-depressive disease as a specific illness stems from the clinical observations of Falret (1854) and Baillarger (1854). In addition to manic-depressive disease, the term "endogenous depression" is now applied to single episodes of depression which are thought to be aetiologically distinct from manic-depressive disease. Further, many authors distinguish a subgroup of single depressions which are said to occur characteristically at the involutional period (involutional depression). These variants of endcgenous depression are thought to be illnesses throughout which the patient retains the potentiality of complete remission.

These illnesses occur typically in individuals with certain constitutional characteristics and are probably genetically distinct. Thus we are dealing with two sets of physiological and psychological phenomena: those which characterize the illnesses or attack states and differentiate patients from well people, and those which distinguish the constitutional make-up of individuals who are prone to these types of illness. The former phenomena should disappear with spontaneous remission or with successful trcatment ; the latter are likely to persist unless the treatment produces a change in the constitution which may provide protection against future attacks. In any attempt, therefore, to seek diagnostic criteria it is important to distinguish between these two sets of physiological and psychological phenomena.

One of the classic symptoms of endogenous depression is a diurnal variation in mood and symptomatology, which was, we believe, first described by Schneider (1920). In physiological depression the depressive process is typically at its maximum in the early hours of the morning, and tends to improve during the day. In psychogenic or reactive depression it is said that each new day starts more hopefully than it finishes.

Diurnal rhythms in physiological functions are common in normal subjects (Vogel, 1854 ; Kleitman, 1939 ; Stanbury and

\footnotetext{
* Department of Psychological Medicine, the Royal Free Hospital,

London.
tDivision of Human Physiology, the National Institute for Medical Research, London.
}

Thompson, 1951 ; Aschoff and Wever, 1962), and the disruption of the normal pattern of the sleep and wakefulness in depressive disease suggests that it might be worth looking for abnormalities in other physiological functions which normally show diurnal rhythms.

Kleitman (1939), as a result of extensive studies on sleep and wakefulness, concluded that the human cycle of waking and sleeping reflects a biological cycle of fatigue and recovery which becomes, early in life, locked into a 24-hour day through environmentally or culturally determined patterns of activity. Kleitman concluded that all biological diurnal rhythms are determined by this basic pattern of activity and inactivity. It has consequently become widely believed that changes in such rhythms in manic-depressive diseases are likely to be secondary and of little theoretical importance. It is therefor of some interest to note that Kleitman did in fact record that individuals vary considerably in the lability with which their biological rhythm changes in relation to alterations in working schedules. He noted that pyknic and extroverted individuals adapt most rapidly to irregular schedules. Pyknic physiques are constitutional characteristics said to be associated with manic-depressive disease. Kleitman considered the fixity of biological rhythms as primarily a function of individual constitutional differences, but he did note an observation of Lindhard's that some rhythmic physiological functions are more inherent and less easily changed than others.

\begin{tabular}{|c|c|c|}
\hline Rhythm & Type of Response to an Abnormal Routine & Reference \\
\hline $\begin{array}{l}\text { Heart rate } \\
\text { Blood pressure }\end{array}$ & Entirely environmental. & $\left\{\begin{array}{l}2 \\
2\end{array}\right.$ \\
\hline $\begin{array}{l}\text { Phosphate excretion } \\
\text { Body temperature }\end{array}$ & $\begin{array}{l}\text { Largely environmental, though evidence of } \\
\text { an inherent 24-hour rhythm in some } \\
\text { subjects. }\end{array}$ & $\left\{\begin{array}{l}1,3 \\
1,2,7\end{array}\right.$ \\
\hline $\begin{array}{l}\text { Water excretion } \\
\text { Chloride excretion } \\
\text { Sodium excretion }\end{array}$ & $\begin{array}{l}\text { Marked inherent 24-hour rhythm, which } \\
\text { may be very pronounced in many subjects. }\end{array}$ & $\left\{\begin{array}{l}1,4,6,7 \\
1,3,6,7 \\
1,3,5\end{array}\right.$ \\
\hline Potassium excretion & $\begin{array}{l}\text { Very marked 24-hour rhythm, usually pre- } \\
\text { dominating over any environmental } \\
\text { influence. }\end{array}$ & $1,3,5$, \\
\hline
\end{tabular}

References: 1, Mills and Stanbury (1952). 2, Kleitman and Kleitman (1953) 3, Mills, Thomas, and Yates (1954). 4, Lewis, Lobban, and Shaw (1956) 5 , Lewis and Lobban (1956). 6, Lewis and Lobban (1957a). 7, Lewis and
Lobban (1957b).

Recent work by one of us in collaboration with P. R. Lewis (Lewis and Lobban, 1957b) has outlined these differences. The accompanying Table shows that different diurnal rhythms vary considerably in the ease with which they change when the subiect's activity is determined by different time routines. Thus diurnal rhythms in blood pressure and in pulse rate are primarily environmental and the variations in phosphate excretion and in body temperature are largely environmental, though in some subjects there is evidence for an inherent 24-hour rhythm. On the other hand, the 24-hour rhythms in the excretion or water, chloride, sodium, and potassium are more resistant to change. In most subjects, however, even these rhythms will shift after varying periods on an abnormal schedule. 
The present paper reports a study of the diurnal renal rhythms of 36 patients diagnosed as endogenously depressed and those of 43 patients suffering from personality disorders in whom an endogenous depression had been excluded on clinical grounds.

The diagnoses were derived from the history and clinical observations, and were made in the absence of any knowledge of the experimental findings. Patients in whom there was any suspicion of hypomania, schizophrenia, or organic disease were excluded from the analysis. Apart from these exclusions the subjects of the study were consecutive admissions to the inpatient psychiatric unit at the Royal Free Hospital. Observations were also made on other diurnal rhythms-oral temperature, resting pulse, and blood pressure.

\section{Method}

Within four days of admission each patient was placed on a standard regimen which lasted for 38 hours. This began at 20.00 hours, when urine was voided, and this specimen was discarded. Urine collections were subsequently made at 22.30, 02.30, 07.30, 10.00, 12.00, 14.00, 16.00, 18.00, $20.00,22.30,02.30,07.30$, and 10.00 hours. On each occasion the volume and the actual time at which urine was passed were recorded and a specimen kept under toluene for analysis. Potassium and sodium were measured by flame photometry, and chloride was estimated by potentiometric titration against one-tenth normal silver nitrate with acetic acid as the titration medium (Sanderson, 1952). The results were expressed as the mean output of each electrolyte during the period since the last urine collection. At the time of each urine collection the oral temperature was taken over three minutes.

All patients were up and about during testing, and from breakfast on the first morning of the test period up to supper on the evening of the same day received a standard diet. Fluids were allowed freely and the intake was recorded. Medication was continued.

(a)
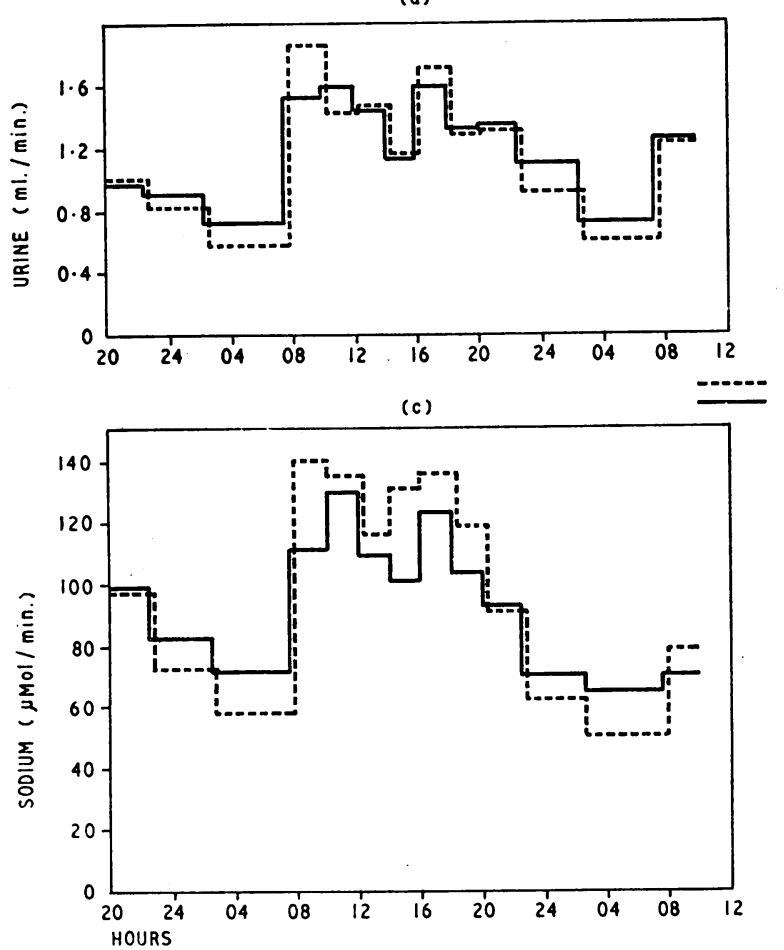

\section{Results}

The results for the urinary constituents are given in Fig. 1. A clear diurnal variation is seen in all cases, with the excretory rates being higher between 07.30 and 22.30 hours. This variation is less marked for the depressed patients in respect of sodium, potassium, and chloride. This reduction in diurnal variation is also present for the urine volume, but the difference between the groups is not so great. For sodium and chloride the differences between the groups are statistically significant. These findings cannot be related to overall differences in the output of water or electrolytes. The endogenous patients excrete a larger urine volume at night, but this difference and the daytime differences between the groups are not significant. For potassium the night excretion rates are similar for the two groups but are consistently lower for the endogenous group during the daytime. These latter patients excrete more sodium and chloride at night and less during the daytime. The differences between the group means for the seven daytime periods in the endogenous and control patients are significant in the case of potassium $(P<0.02)$, sodium $(P<0.02)$, and chloride $(P<0.001)$. The differences between the mean outputs at night are also significant for sodium $(P<0.01)$ and chloride $(P<0.01)$, but not for potassium.

The total output of sodium and chloride for the control patients is not significantly different from that for the endogenous patients. If the values for the two night periods (20.00 to 07.30 hours) are averaged, the mean 24-hour total sodium output for the former group is $143.9 \mathrm{mM}$ and for the latter group $142.8 \mathrm{mM}$. For chloride the figures are 142.6 and $134.7 \mathrm{mM}$ respectively.

The night excretory rates for sodium and chloride, but not for water and potassium, are less for the second night, and the matutinal rise is diminished. These findings are the same for both diagnostic groups. Reconsideration of the standard diet showed that this had a low salt content $(80 \mathrm{mEq}$ of sodium per day). This affected both groups in a similar way.

(b)
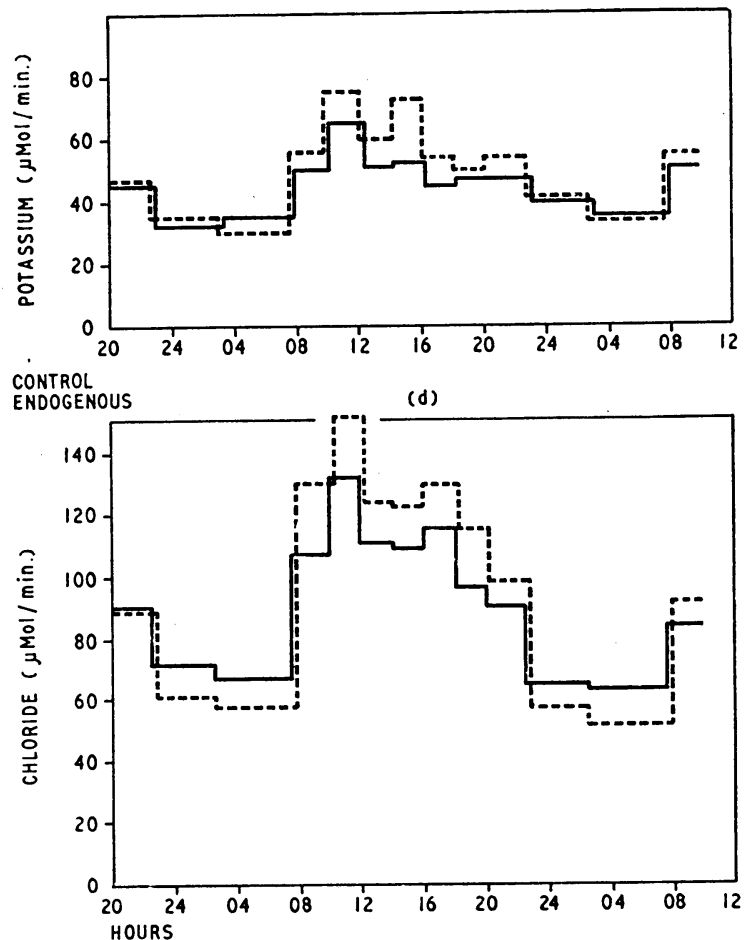

Fig. 1.-Mean excretion rates for (a) urine volume, (b) potassium, (c) sodium, and (d) chloride are plotted for each collection period for the control and the endogenously depressed groups. For the latter group the excretion rate of sodium and chloride is consistently lower during the day and higher at night. The effect is less marked with potassium and absent for urine volume. 


\section{Individual Results}

There were a number of differences between the two groups of patients other than their diagnostic status, and it is therefore important to examine the individual results.

In comparing individual diurnal rhythms it is convenient to use the day/night ratio (Lewis, Lobban, and Shaw, 1956). In the present investigations the morning specimen was collected at 07.30 hours and the last daytime specimen was collected at 20.00 hours. The figure for this $12 \frac{1}{2}$-hour period has therefore been prorated to 12 hours and the resulting figure related to the mean value for the two night periods similarly adjusted. The day/night ratio thus obtained is presented as the daytime percentage output.

The major difference between the two groups of patients other than their diagnostic status were age, medication, and sex. Unfortunately the condition of many patients precluded the possibility of their ceasing treatment for the test, and we have therefore examined the relation of the day/night ratios to medication. All patients received a barbiturate at night. Twenty-two patients (endogenous 7 , control 15) received no medication during the day, while 24 (endogenous 10, control 14) were receiving barbiturates, 19 (endogenous 11 , control 8 )
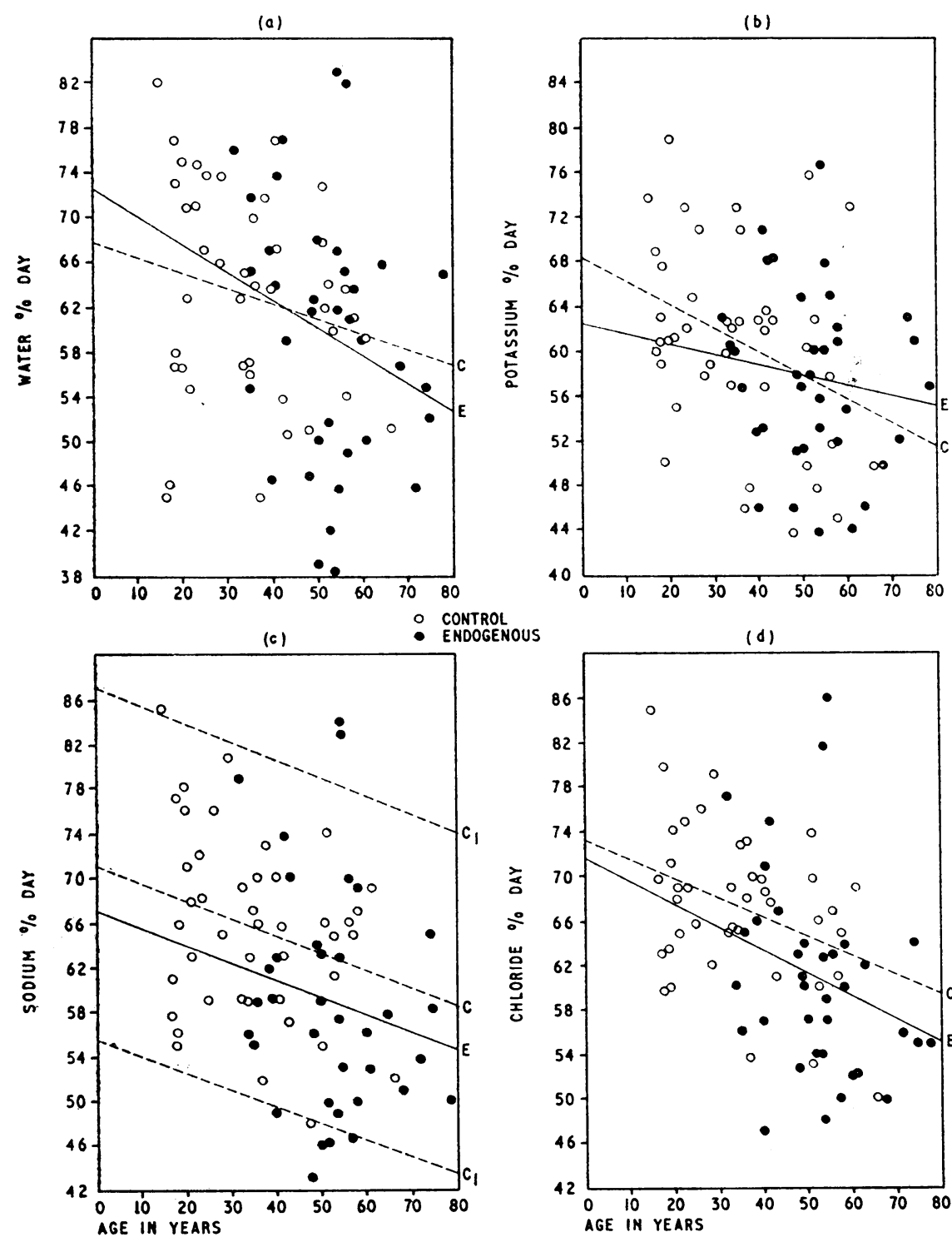

FIG 2-Day/night partitions for each constituent, together with the regression lines, are plotted against age. In the case of sodium the confidence limits at 2 S.D. are also giver. plotted against age. In the case of sodium the confidence limits at 2 S.D. are also given. The equations for the regressions are as follows. The values for the control group are given
first. For urine, vol. $\mathrm{Y}=67.86-0.138 \mathrm{X}, \mathrm{Y}=72.44-0.245 \mathrm{X}$; for potassium, $\mathrm{Y}=68.23$ $-0.209 \mathrm{X}, \mathrm{Y}=62.49-0.095 \mathrm{X}$; for sodium, $\mathrm{Y}=71.16-0.162 \mathrm{X}, \mathrm{Y}=67.33-0.159 \mathrm{X}$; for chloride, $\mathrm{Y}=73.50-0.181 \mathrm{X}, \mathrm{Y}=71.50-0.206 \mathrm{X}$. were on phenothiazines, 25 (endogenous 17 , control 8) were on antidepressants, and 9 (endogenous 4, control 5) were on chlordiazepoxide.

To test the effect of medication the Mann Whitney $U$ test for rank differences was used to compare each group of patients on each drug with the remaining patients. In no case was the ifference significant.

Only 11 subjects were men (endogenous 6, control 5), and the mean day/night ratio for men was not significantly different from that for the females.

As might be expected, the mean age of the endogenous group (52.4, range 32-78 years) was considerably greater than that of the control group (35, range 17-66 years). It has not been possible to find any previous reports of the effect of age on the rhythms discussed here. Clearly the differences between our two groups might reflect their age differences. In Fig. 2 the day/night ratios are plotted against age, and it can

The regression on age is similar for the excretion of water, potassium, sodium, and chloride. For the control group the product moment correlations on age for potassium and sodium are -0.347 and -0.289 , of which the former is significant $(\mathrm{P}<0.05)$. For the endogenous group the correlations are -0.142 and -0.182 respectively, neither reaching statistical significance. If both groups are combined the correlations for potassium and sodium are -0.330 and -0.370 , which are both significant $(P<0.01$ and $P<0.001$ respectively).

The regression equations for both groups are very similar. In the case of sodium and chloride the slopes are similar, but at all ages the mean day/night ratio is lower for the endogenous group than for the controls. If the values for the former group are compared with the expected values derived from the latter group they are found to be significantly lower in the case of both sodium $(P<0.05)$ and chloride $(P<0.05)$. This test of significance, however, is sensitive to the imbalance in age between the two groups, and the results were not confirmed by an analysis of covariance undertaken for the figures for sodium $(\mathrm{F}=2.36, \mathrm{P}>0.05)$.

The range of normal day/night ratios, except for a group of volunteers studied by two of us (Lobban and Tredre, unpublished data), has not so far as we know been delineated. In this group day partitions below $60 \%$ were unusual, and, while the present study includes older subjects, day partitions around $50 \%$ or below may well be abnormal.

In the present study 17 patients had sodium day partitions below $55 \%$. Of these, 13 were in the endogenous group and only four in the control group. Of these four controls three made some significant complaint of depression. The fourth, although she complained primarily of anxiety, was subsequently given electric convulsion therapy, but without apparent improvement.

The validity of the distinction between endogenous and exogenous depressive reactions is bcoming increasingly accepted, and has been placed on a firm statistical basis by the work of Hamilton and White (1959), Kiloh, Ball, and Garside (1962), and Kiloh and Garside (1963). However, diag- 
nosis in the individual case presents great difficulty. In the present study the physiological findings were not available before the patients were finally diagnosed, but in some cases the results would have provided useful additional information. For example, a woman of 54 was admitted for investigation of monosymptomatic facial pain, and, although she did not complain of depression, this was felt to be an early presentation of an involutional depression. Some months later she suddenly made a serious suicidal attempt and was readmitted deeply depressed. At the time of her first admission her sodium day partition was found to be $49 \%$. Another patient was transferred from a medical ward for investigation of increasing hysterical behaviour. It became clear that these symptoms reflected an underlying endogenous depression, and the patient recovered with electric convulsion therapy. At the time of her transfer her sodium day partition was $46 \%$. There were other patients in the group with typical symptomatology and normal rhythms, so that further work is needed to clarify these inconsistencies.

\section{Other Rhythms}

During this investigation diurnal variations in body temperature, blood pressure, pulse rate, and, in the case of some patients, reaction times were also studied. These findings have been reported elsewhere (Bridges, 1965). Apart from body temperature no significant differences between the groups were observed. The changes with body temperature, which showed a characteristic diurnal variation in both groups, presented no consistent differences between the groups except for a slight tendency for the endogenous group to have a lower body temperature throughout, the differences being most pronounced in the morning and early evening. Only at 10.00 hours were these differences significant.

\section{Discussion}

The results that we previously reported on a smaller series of 45 patients have been generally confirmed in the present study (Lobban, Tredre, Elithorn, and Bridges, 1963).

The present findings are only suggestive, but flattening of diurnal rhythms in depressed patients has been reported by Takuma (1959) and by Folk (1961). Palmai and Blackwell (1965) have shown a reversal of the diurnal rhythm of salivary excretion in depressive patients with a return to normal after successful treatment with electric convulsion therapy. Sakai (1960) has related variations in the diurnal rhythms of 17-ketosteroid excretion to endogenous depressive illness, and though the relation between adrenocorticoids and the control of diurnal rhythms is uncertain (Martel, Sharp, Slorach, and Vipond, 1962) it seems likely that the mechanisms governing the two rhythms will be closely related.

Anderson and Dawson (1963) have shown that electrolyte changes tend to be found in a subgroup of depressive illnesses and the relation of electrolyte metabolism to depressive mood changes has been reviewed by Coppen, Shaw, and Mangoni (1962).

It may be argued that physiological changes associated with diurnal variations in mood may be secondary to behavioural changes. It is difficult to refute this argument in the present study, but changes in the diurnal rhythms of those functions which are most sensitive to environmental factors-bloodpressure, pulse rate, and body temperature-appeared less marked than those functions which are thought to depend more upon an inherent 24-hour rhythm.

In the early years of the century psychiatry was essentially organic in outlook, but in recent years there has been a tendency to relate all psychological symptoms to psychological causes and even to attribute many clearly physical changes to psychological stress. The neuroticizing effect of minor physiological disabilities is now becoming more widely recognized. For example, it has been shown that the effective treatment of enuresis may relieve a neurosis which is secondary to the habit disorder. Clinical observations with manic-depressives suggest that the behavioural disability which accompanies the endogenous mood change reflects in part a response determined by personality factors to perceived physiological changes. Whether or not these changes are primary in some depressive illnesses, it seems probable that further studies of such changes will be of value in classifying these illnesses and allowing a more rational approach to treatment.

\section{Summary}

Observations have been made on the diurnal rhythms of water and electrolyte excretion in 79 psychiatric patients. Thirty-six patients with a diagnosis of endogenous depression contrasted with 43 control patients with personality disorders and neuroses showed on average a reduction in amplitude in the rhythms of water, potassium, sodium, and chloride excretion, the effect being most pronounced with sodium and chloride. Part of the effect could be related to age differences between the two groups, and it was shown that in both groups the amplitude of the diurnal variations decreased with age.

Similar observations have been reported by other workers, and it is suggested that the physiological components of psychological stress have been too frequently dismissed as secondary to changes in behaviour.

We are grateful to Dr. S. W. Hardwick for allowing us to study patients under his care, and to Sister B. Guiver. Mrs. M. Kerr kindly carried out the statistical calculations, and we thank Dr. Y. Machiyama for a translation of a Japanese paper. We are indebted to Mrs. E. Turner for secretarial help.

One of us (P.K. B.) was supported by the Mental Health Research Fund, and the rest of us by the Medical Research Council.

\section{REFERENCES}

Anderson, W. McC., and Dawson, J. (1963). Brit. F. Psychiat., 109, 225. Aschoff, J., and Wever, R. (1962). Naturwissenschaften, 49, 337 Baillarger, M. (1854). Bull. Acad. Méd. (Paris), 19, 340.

Bridges, P. K. (1965). M.D. Thesis, University of London.

Coppen, A., Shaw, D. M., and Mangoni, A. (1962). Brit. med. F., 2, 295.

Falret, J. P. (1854). Leçons Cliniques de Médecine Mentale, Pt. 1, Symptomatologie Générale. Baillière, Paris.

Folk, G. E. (1961). In Circadian Systems. Report of 39th Ross Conference on Paediatric Research, p. 86. Ross, Ohio.

Hamilton, M., and White, J. M. (1959). F. ment. Sci., 105, 985.

Kiloh, L. G., Ball, J. R. B., and Garside, R. F. (1962). Brit. med. F., 1, 1225 .

and Garside, R. F. (1963). Brit. 7. Psychiat., 109, 451.

Kleitman, N. (1939). Sleep and Wakefulness. Univ. of Chicago Press, Chicago.

Chicago. jeitman, E. (1953). 7. appl. Physiol., 6, 283.

Lewis, P. R. and Lobban, M. C. (1956). F. Physiol. (Lond.), 133, 670. Lewis, P. R., (1957a). Ouart. 7. exp. Physiol., 42, 356. (1957b). Quart. 7. exp.

- (1957b). Obid., 42, 395). 7. Physiol. (Lond.), 133, 659

Lobban, M., Tredre, B., Elithorn, A., and Bridges, P.' (1963). Nature (Lond.), 199, 667.

Martel, P. J., Sharp, G. W. G., Slorach, S. A., and Vipond, H. J. (1962). f. Endocr., 24, 159 .

Mills, J. N., and Stanbury, S. W. (1952). F. Physiol. (Lond.), 117, 22 Thomas, S., and Yates, P. A. (1954). Ibid., 125, 466.

Palmai, G., and Blackwell, B. (1965). Brit. F. Psychiat., 111, 334.

Sakai, M." (1960). Yokohama med. Bull., 11, 352.

Sakai, M. (1960). Yokohama med. Bll., $52,502$.

Sanderson, P. H. (1920). Z. ges. Neurol. Psychiat., 59, 281.

Schneider, K. (1920), Z. ges. Neurol. Psychiat., 59, 281. 10, 267

Stanbury, S W., and Thomson A. E. (1951), Clin.

Takuma, T. (1959). Clin. Psychiat. (7apan, 1, 325 . Vogel, J. (1954). Archiv des Vereins für Gemeinschaftlich
Förderung der Wissenschaftlichen Heilkunde, 1, 96. 